\title{
Relationships between Extratropical Sea Level Pressure Variations and the Central Pacific and Eastern Pacific Types of ENSO
}

\author{
JiN-Yi Yu AND SEON TAE KIM \\ Department of Earth System Science, University of California, Irvine, Irvine, California
}

(Manuscript received 22 February 2010, in final form 9 August 2010)

\begin{abstract}
This study examines the linkages between leading patterns of interannual sea level pressure (SLP) variability over the extratropical Pacific $\left(20^{\circ}-60^{\circ} \mathrm{N}\right)$ and the eastern Pacific (EP) and central Pacific (CP) types of El Niño-Southern Oscillation (ENSO). The first empirical orthogonal function (EOF) mode of the extratropical SLP anomalies represents variations of the Aleutian low, and the second EOF mode represents the North Pacific Oscillation (NPO) and is characterized by a meridional SLP anomaly dipole with a nodal point near $50^{\circ} \mathrm{N}$. It is shown that a fraction of the first SLP mode can be excited by both the EP and CP types of ENSO. The SLP response to the EP type is stronger and more immediate. The tropical-extratropical teleconnection appears to act more slowly for the CP ENSO. During the decay phase of EP events, the associated extratropical SLP anomalies shift from the first SLP mode to the second SLP mode. As the second SLP mode grows, subtropical SST anomalies are induced beneath via surface heat flux anomalies. The SST anomalies persist after the peak in strength of the second SLP mode, likely because of the seasonal footprinting mechanism, and lead to the development of the CP type of ENSO. This study shows that the CP ENSO is an extratropically excited mode of tropical Pacific variability and also suggests that the decay of an EP type of ENSO can lead to the onset of a CP type of ENSO with the aid of the NPO. This extratropical linking mechanism appears to be at work during the 1972, 1982, and 1997 strong El Niño events, which were all EP events and were all followed by strong CP La Niña events after the NPO was excited in the extratropics. This study concludes that extratropical SLP variations play an important role in exciting the CP type of ENSO and in linking the transitions from the EP to CP events.
\end{abstract}

\section{Introduction}

It is becoming increasingly recognized that there are two different types of El Niño-Southern Oscillation (ENSO; Larkin and Harrison 2005; Yu and Kao 2007; Ashok et al. 2007; Kao and Yu 2009; Kug et al. 2009). One type is characterized by sea surface temperature (SST) anomalies centered in the tropical eastern Pacific, and the other by SST anomalies centered in the tropical central Pacific. Kao and Yu (2009) refer to these two types as the eastern Pacific (EP) and central Pacific (CP) types, respectively. Different terms have also been used to describe the CP type, including "dateline El Niño" (Larkin and Harrison 2005), "El Niño Modoki" (Ashok et al. 2007), and "warm pool El Niño" (Kug et al. 2009). Studies have shown that these two ENSO types have

Corresponding author address: Dr. Jin-Yi Yu, Department of Earth System Science, University of California, Irvine, Irvine, CA 92697-3100.

E-mail: jyyu@uci.edu different impacts on global weather and climate (e.g., Larkin and Harrison 2005; Kao and Yu 2009; Weng et al. 2009; Kim et al. 2009; Yeh et al. 2009). Before this twotype view of ENSO emerged, El Niño was already known to produce teleconnections with the extratropics by forcing sea level pressure (SLP) variations characterized by a deepened Aleutian low and a ridge downstream over North America (Horel and Wallace 1981). This wavelike pattern resembles the so-called Pacific-North America (PNA) teleconnection pattern (Wallace and Gutzler 1981). It has also been suggested that the extratropical SLP response to ENSO can be sensitive to the longitudinal position of the tropical SST anomalies (Mo and Higgins 1998). An obvious question is then whether the extratropical SLP variations associated with the CP ENSO are similar to or different from those described for the conventional EP ENSO. An answer to this question is crucial to contrast and explain the global impacts of these two types of tropical SST variability.

Previous studies have also suggested that extratropical SLP variations can influence the occurrence of 
El Niño events. A seasonal footprinting mechanism was proposed by Vimont et al. (2001, 2003, 2009) to suggest how midlatitude atmospheric variability could lead to tropical SST variability via atmosphere-ocean coupling in the subtropics. These extratropical and subtropical airsea interactions were suggested to be capable of leading to the onset of El Niño events (Anderson 2003, 2004; Chang et al. 2007). These views suggest that extratropical SLP variations can force ENSO events, which is opposite to the interaction mentioned in the previous paragraph in which ENSO SST variability forces extratropical SLP variations. In this study, we examine force-and-response relationships between extratropical SLP variations and tropical Pacific SST variations associated with the EP and CP types of ENSO.

\section{Data and EOF analysis}

Two datasets are used in this study. For the SST, we use the Extended Reconstruction of Historical Sea Surface Temperature version 3 (ERSST V3; Smith and Reynolds 2003) from the National Climate Data Center (NCDC). For the atmospheric fields, we use the National Centers for Environmental Prediction (NCEP)-National Center for Atmospheric Research (NCAR) reanalysis (Kistler et al. 2001). We choose to analyze the period 1958-2007, during which both the ERSST and NCEP-NCAR reanalysis are available. Anomalous quantities are computed by removing the monthly mean climatology and a linear trend. A running mean with a boxcar filter is applied to the anomalies to remove variability shorter than 12 months.

We first perform empirical orthogonal function (EOF) analysis to identify the leading patterns of interannual SLP variations in the extratropical Pacific. The EOF analysis is applied to the covariance matrix of monthly SLP anomalies between $20^{\circ}$ and $60^{\circ} \mathrm{N}$ and between $120^{\circ} \mathrm{E}$ and $80^{\circ} \mathrm{W}$. The first two leading EOF modes are shown in Fig. 1. The first EOF mode (Fig. 1a) explains $40 \%$ of the total SLP variance and is characterized by a SLP anomaly pattern that has large values in the North Pacific where the Aleutian low is located. Therefore, this SLP mode represents interannual variations of the Aleutian low. The second EOF mode (Fig. 1b) explains $16 \%$ of the total SLP variance and is characterized by out-of-phase SLP variations between the subtropical Pacific $\left(20^{\circ}-40^{\circ} \mathrm{N}\right)$ and the higher-latitude Pacific $\left(50^{\circ}-60^{\circ} \mathrm{N}\right)$. This mode resembles the so-called North Pacific Oscillation (NPO; Walker and Bliss 1932; Rogers 1981). To examine the SLP anomalies associated with these two modes over other parts of the Pacific, SLP anomalies between $30^{\circ} \mathrm{S}$ and $60^{\circ} \mathrm{N}$ are regressed onto the principal components (PCs) of these two EOF modes (PC1 and PC2 hereafter). The results are shown in Figs. 1c,d, where the regression coefficients that are significant at the 99\% level using a Student's $t$ test are shaded. For the first EOF mode, Aleutian low variations are associated with significant tropical SLP anomalies that are out of phase between the eastern and western Pacific (Fig. 1c). The tropical SLP anomaly pattern resembles the Southern Oscillation pattern. Because SLP anomalies in the tropics are typically much smaller than those in the higher latitudes (Kutzbach 1970; Kidson 1975), we also show in Fig. 1e the correlation coefficients between PC1 and basinwide Pacific SLP anomalies. The Southern Oscillation pattern is better revealed in this figure in which the SLP anomalies have been normalized by their local standard deviations. For the second EOF mode, the associated SLP anomalies extend to the tropical central Pacific from the southern center of the NPO, as is evident in both the regression and correlation analyses (Figs. 1d,f).

\section{Aleutian low variations and the EP and CP types of ENSO}

We next identify the SST anomalies associated with these two SLP variation modes by regressing Pacific SST anomalies onto the PCs of the two SLP modes. As shown in Fig. 2, the first SLP mode is associated with a typical ENSO SST pattern in the tropical Pacific whose SST anomaly center is located in the eastern Pacific and attached to the South America coast; these are both major characteristics of the EP type of ENSO identified by Kao and Yu (2009). The pattern correlation between the SST regression pattern shown in Fig. 2 between $20^{\circ} \mathrm{S}$ and $20^{\circ} \mathrm{N}$ and the SST anomaly pattern obtained by Kao and $\mathrm{Yu}$ (2009; their Fig. 3) for the EP ENSO is 0.83, which is larger than the corresponding pattern correlation with the CP ENSO (0.59). To further examine the relations between the first SLP mode and the EP and CP types of ENSO, we calculate the lead-lag correlations between PC1 and the SST indices for these two types of ENSOs (the EP and CP indices, hereafter). Both indices are obtained from Kao and Yu (2009), where a combined regression EOF method [similar to the conditional EOF of An (2003)] was used to separate the CP and EP types of ENSO. To obtain the SST EOF pattern for the CP ENSO, they removed SST anomalies regressed with the Niño- $1+2\left(0^{\circ}-10^{\circ} \mathrm{S}, 90^{\circ}-80^{\circ} \mathrm{W}\right) \mathrm{SST}$ index (which represents the influence of the EP type) and then applied EOF analysis to the residual anomalies. The monthly values of the principal component of this CP EOF are the CP index, which is used to indicate the strength of the CP ENSO. Similarly, the EP index is the principal component of the EP EOF of the residual SST anomalies where SSTs regressed with the Niño-4 $\left(5^{\circ} \mathrm{S}-5^{\circ} \mathrm{N}\right.$, $\left.160^{\circ} \mathrm{E}-150^{\circ} \mathrm{W}\right) \mathrm{SST}$ index were removed. The lead-lag 
(a) EOF 1 of SLPA $(40 \%)$

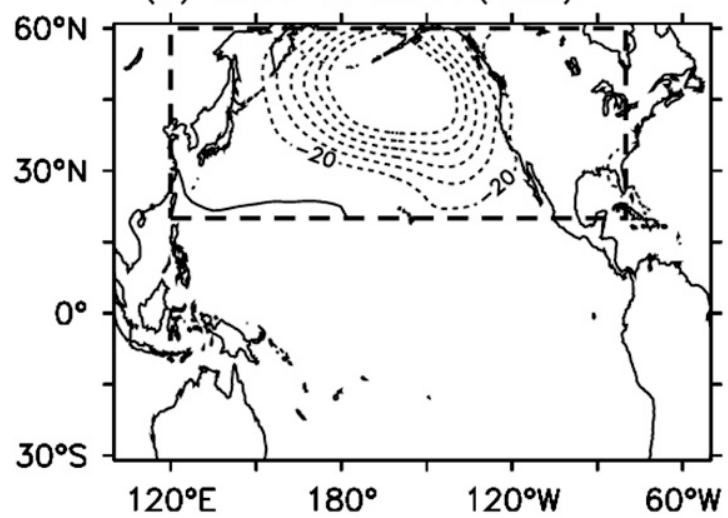

(c) SLP regression on PC1

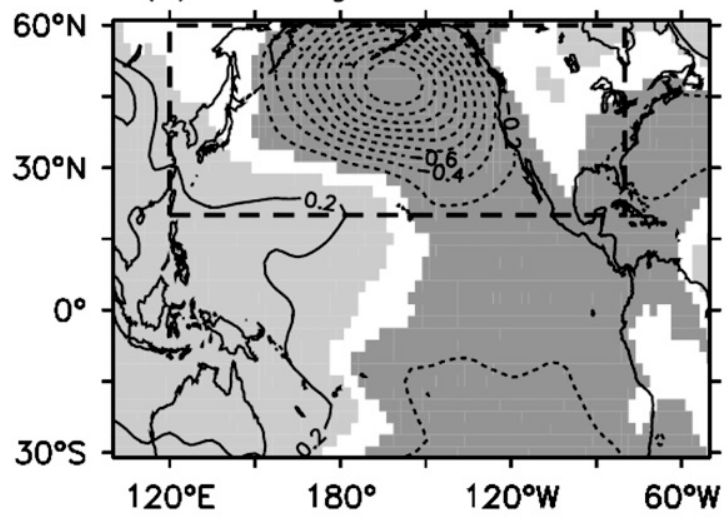

(e) Correlation b/w SLP and PC1

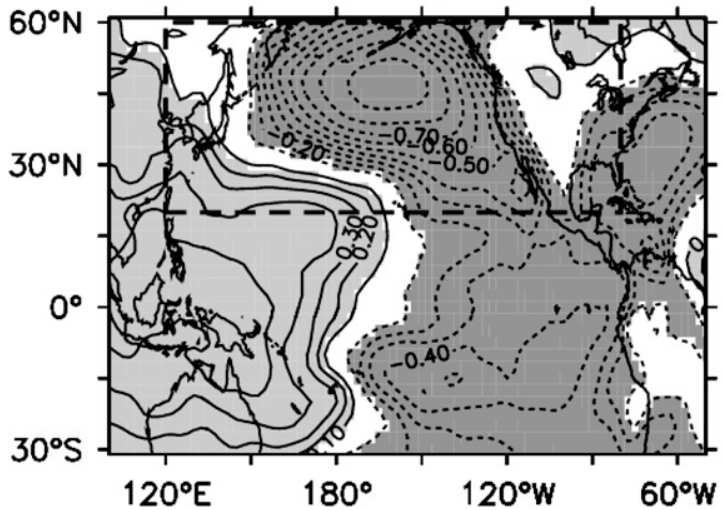

(b) EOF2 of SLPA (16\%)

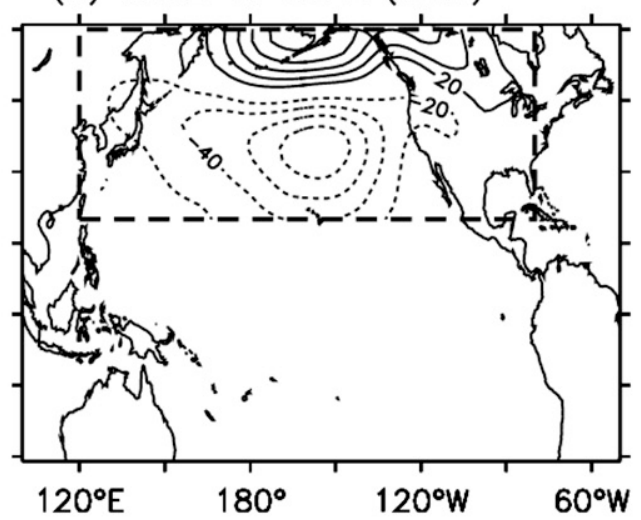

(d) SLP regression on PC2

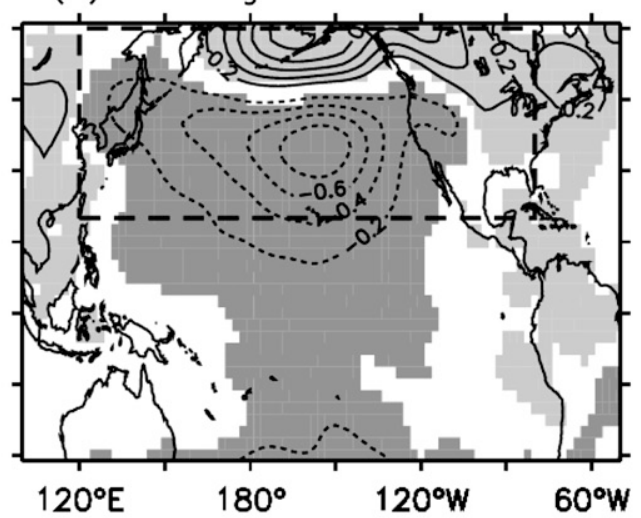

(f) Correlation $b / w$ SLP and PC2

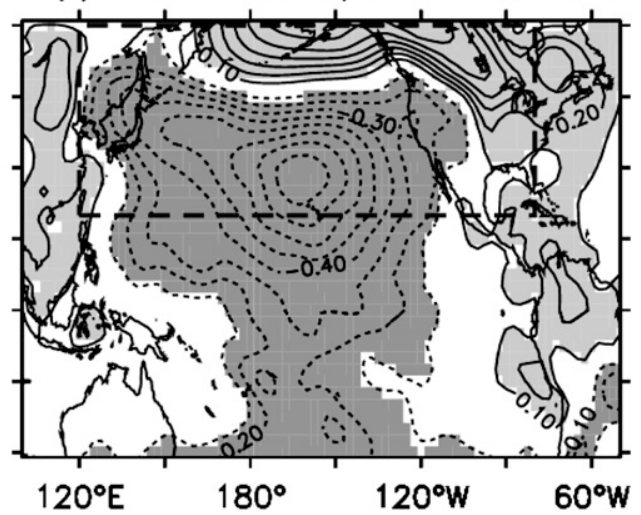

FIG. 1. The (a) first and (b) second EOF modes of interannual extratropical Pacific sea level pressure (SLP) variability for the period 1958-2007. The first mode explains $40 \%$ of the interannual SLP variance, and the second mode explains $16 \%$ of the variance. Panels (c) and (d) [(e) and (f)] show the Pacific SLP anomalies regressed (correlated) with the PCs of the first and second EOF modes, respectively. Contour intervals are 20 for the EOF modes, 0.2 for the regression patterns, and 0.1 for the correlation patterns. For the regression and correlation pattern, the values that are significant at the $99 \%$ level (Student's $t$ test) are shaded.

correlation coefficients between the first SLP mode (i.e., PC1) and the EP and CP indices are shown in Fig. 3. The EP index has a larger correlation with the first SLP mode than the $\mathrm{CP}$ index does (0.29 and 0.24 , respectively, significant at the $99 \%$ level according to a Student's $t$ test).
The largest correlations occur when the EP index leads the first SLP mode by one month and when the CP index leads the first mode by three months. Therefore, although both the EP and CP types of ENSO contribute to interannual variations in the Aleutian low, the Aleutian low 


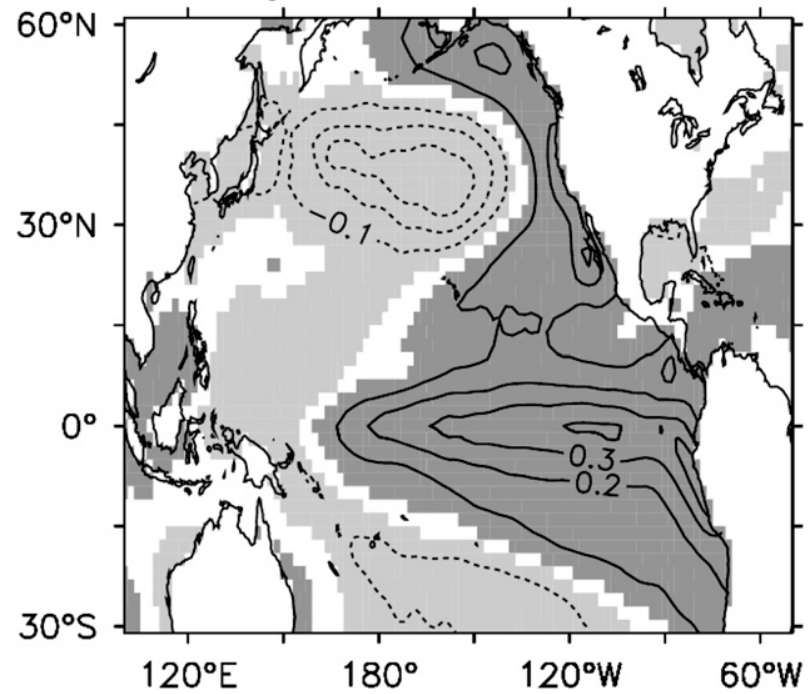

FIG. 2. Pacific SST anomalies regressed with the PC of the first EOF mode of extratropical SLP anomalies. The contour interval is 0.2 and regression coefficients significant at the 99\% level (Student's $t$ test) are shaded.

tends to have a larger and more immediate response to the EP ENSO than to the CP ENSO. The extratropical SLP response to the CP ENSO is two months slower than the response to the EP ENSO.

The correlations shown in Fig. 3 are relatively small although they are significant. The small values imply that tropical SST forcing is just one of the factors that contribute to interannual variations in the Aleutian low. Other processes, such as internal atmospheric dynamics and other lower boundary forcing, must also be important. Another reason for the smaller correlation values is that some of the interannual tropical SST variability is excluded by the regression EOF method used in Kao and Yu (2009) to calculate the EP and CP indices. As mentioned, the indices were calculated from residual SST anomalies after some regressed SST anomalies were removed. This method was designed to increase the independence between the EP and CP indices, which is important for identifying the two types of ENSO. If we use Niño-3 SST anomalies to represent the EP ENSO and Niño-4 SST anomalies to represent the CP ENSO, as in Kug et al. (2009), the largest correlation increases to 0.5 when the Niño-3 index leads the first SLP mode by one month and to 0.4 when the Niño- 4 index leads the SLP mode by three months (not shown). The Aleutian low's response to the SST anomalies in the eastern equatorial Pacific is still stronger and more immediate than to the anomalies in the central equatorial Pacific, which is consistent with Fig. 3. We have also examined individual EP El Niño events to further verify the connection between the EP ENSO and the first SLP mode. Over

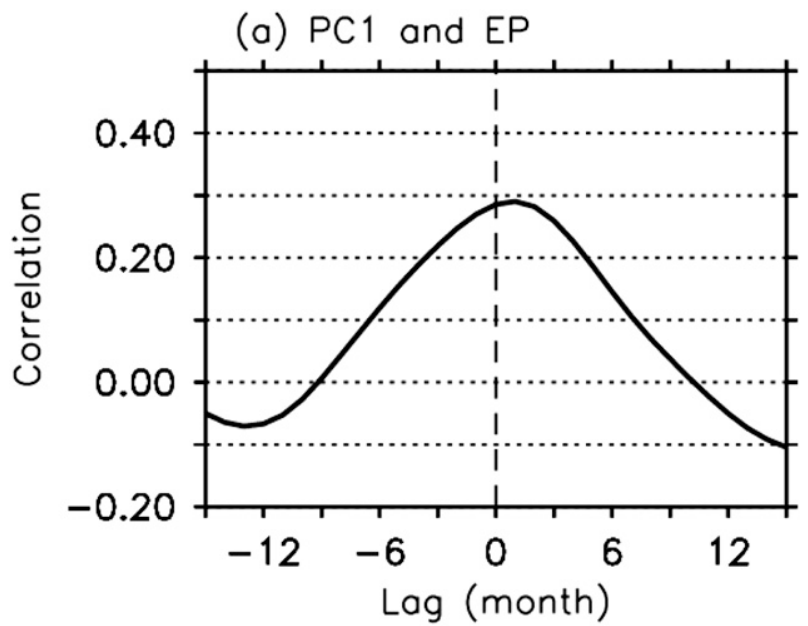

(b) $\mathrm{PC} 1$ and $\mathrm{CP}$

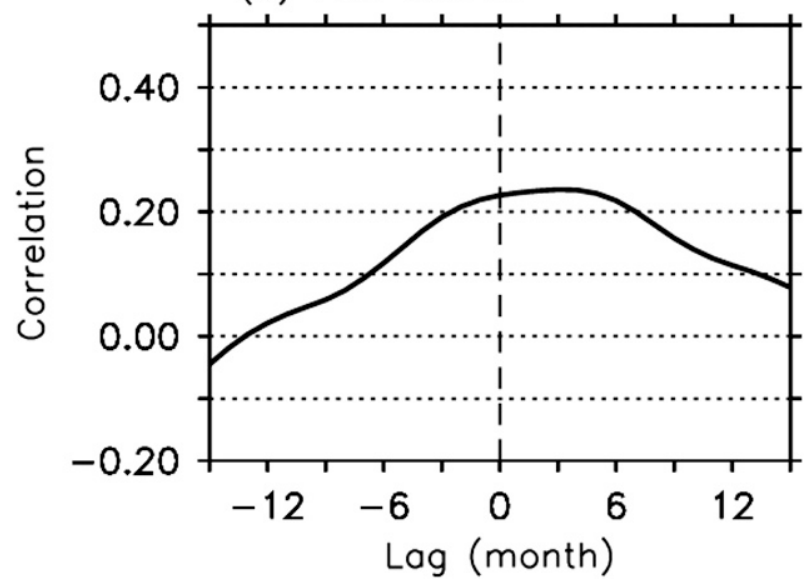

FIG. 3. Lead-lag correlation coefficients between the PC of the first SLP mode and the (a) EP and (b) CP indices. Positive (negative) lags indicate that the $\mathrm{CP} / \mathrm{EP}$ index leads (lags) the PC.

the analysis period 1958-2007, a total of 15 ENSO events can be identified using the National Oceanic and Atmospheric Administration's (NOAA's) Ocean Niño Index. Six of them are considered to be of the EP type and the other nine of the CP type, based on the EP and CP index of $\mathrm{Kao}$ and $\mathrm{Yu}$ (2009) or the subsurface ENSO index of Yu et al. (2011). Winter [December-February (DJF)] SLP anomalies for each of the six EP events are shown in Fig. 4 and their pattern correlation coefficients with the first SLP mode (Fig. 1a) are calculated. The figure shows that except for $1965 / 66$ and $1972 / 73$ events, the seasonally averaged SLP anomaly patterns resemble the first SLP mode with the pattern correlation coefficients ranging from 0.50 to 0.84 . The SLP anomalies composed from these six events (Fig. $4 \mathrm{~g}$ ) have a pattern correlation of 0.81 with the first SLP mode. A similar analysis with the $\mathrm{CP}$ events (not shown) reveals that large pattern correlations (greater than 0.5 ) are found in only four of the nine CP events, which is a smaller 

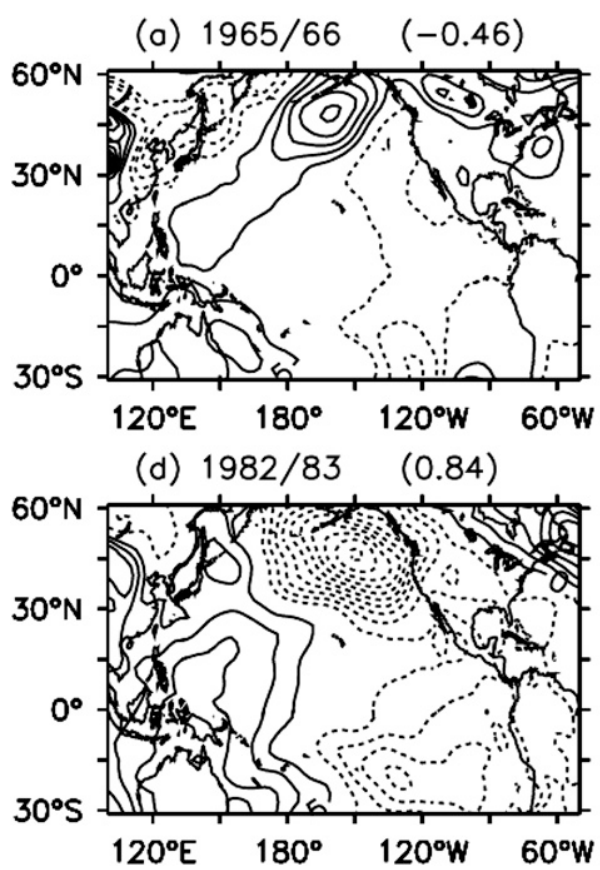

(g) Composite (0.81)

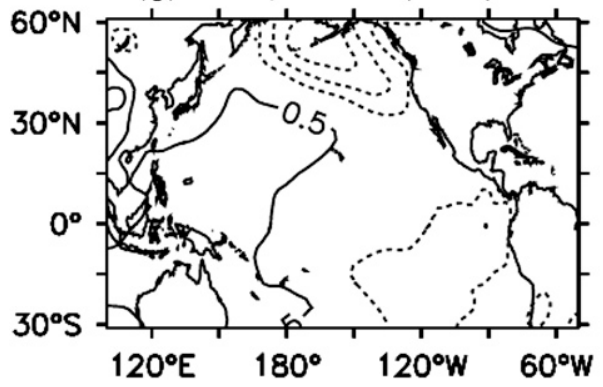

(b) $1972 / 73 \quad$ (0.08)

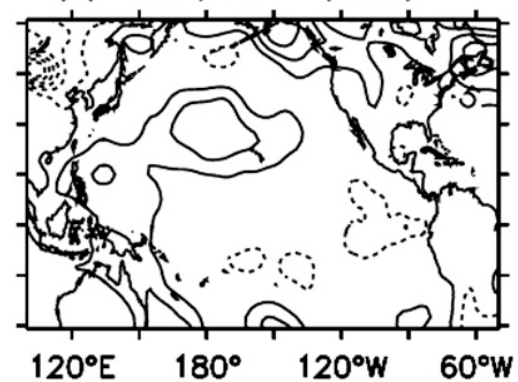

(e) $1987 / 88 \quad(0.54)$

(c) $1976 / 77$

(0.75)

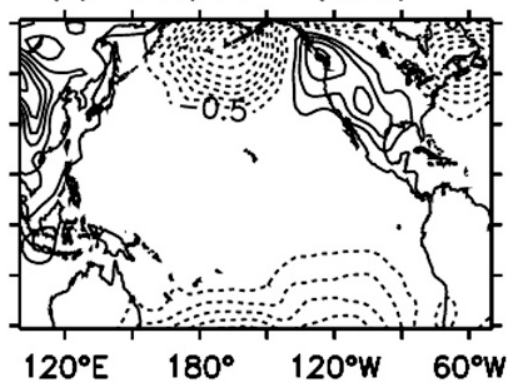

(f) $1997 / 98$

$(0.5)$
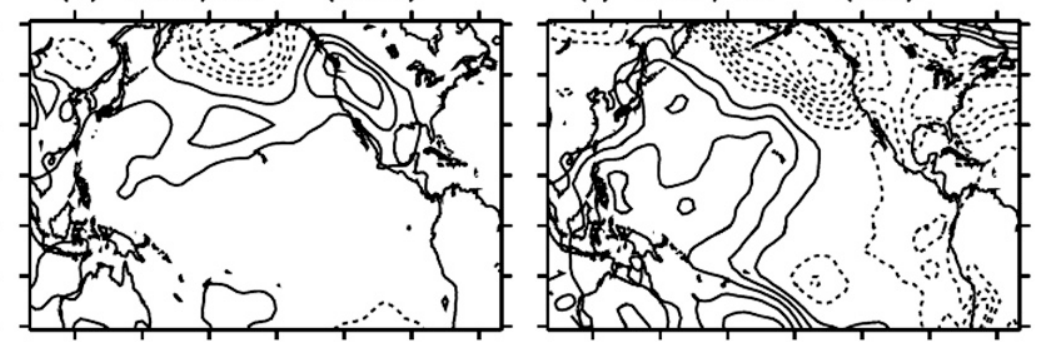

$120^{\circ} \mathrm{E} \quad 180^{\circ} \quad 120^{\circ} \mathrm{W} \quad 60^{\circ} \mathrm{W}$

FIG. 4. Winter (DJF) SLP anomalies for the (a) 1965/66, (b) 1972/73, (c) 1976/77, (d) $1982 / 83$, (e) 1987/88, and (f) 1997/98 EP El Niño events, and (g) the composite of the six events. Pattern correlation coefficients with the first EOF mode of extratropical Pacific SLP anomalies (Fig. 1a) are also shown.

percentage than the EP events (four out of six events). These case studies confirm a stronger association of the Aleutian low (the first SLP mode) with the EP ENSO than with the CP ENSO.

Another major feature in Fig. 2 is a zonally oriented SST anomaly dipole in the central to eastern Pacific between $20^{\circ}$ and $50^{\circ} \mathrm{N}$, which is characterized by a SST anomaly center off the western coast of North America and another anomaly center of opposite sign farther west. Yu et al. (2001) used a long-term simulation of a coupled atmosphere-ocean general circulation model to show that this SST anomaly dipole was forced by surface heat flux anomalies associated with the variations of the Aleutian low. We perform an analysis similar to theirs in Fig. 5 by comparing the regression patterns of SLP, 1000-mb wind, surface heat flux, and SST anomalies with the PC of the first SLP mode. This figure shows that the intensified Aleutian low (i.e., negative SLP anomalies) produces cyclonic wind anomalies (Fig. 5a), which bring warm and moist air to the North American coast to produce positive (into the ocean) surface heat flux anomalies and cold and dry air to the central North Pacific to produce negative surface heat flux anomalies (Fig. 5b). Underneath these two locations, positive and negative centers of the extratropical SST anomaly dipole form (Fig. 5c).

Figure 2, therefore, suggests that the Pacific SST anomaly signatures associated with the first SLP mode are an EP type of ENSO in the tropics and a zonal dipole in the extratropics. To verify the occurrence sequences among these three anomaly patterns, we use three indices to represent their variations and to calculate their lead-lag correlations. The Aleutian low variation (i.e., the first EOF mode) is represented by PC1, the strength of the EP ENSO by the SST anomalies averaged in the eastern equatorial Pacific (between $5^{\circ} \mathrm{S}-5^{\circ} \mathrm{N}$ and $130^{\circ}$ $80^{\circ} \mathrm{W}$ ), and the strength of the extratropical SST anomaly dipole by a dipole index defined as the SST anomaly difference between the eastern $\left(30^{\circ}-45^{\circ} \mathrm{N}, 130^{\circ}-120^{\circ} \mathrm{W}\right)$ and central $\left(30^{\circ}-45^{\circ} \mathrm{N}, 170^{\circ} \mathrm{E}-150^{\circ} \mathrm{W}\right)$ extratropical Pacific. 


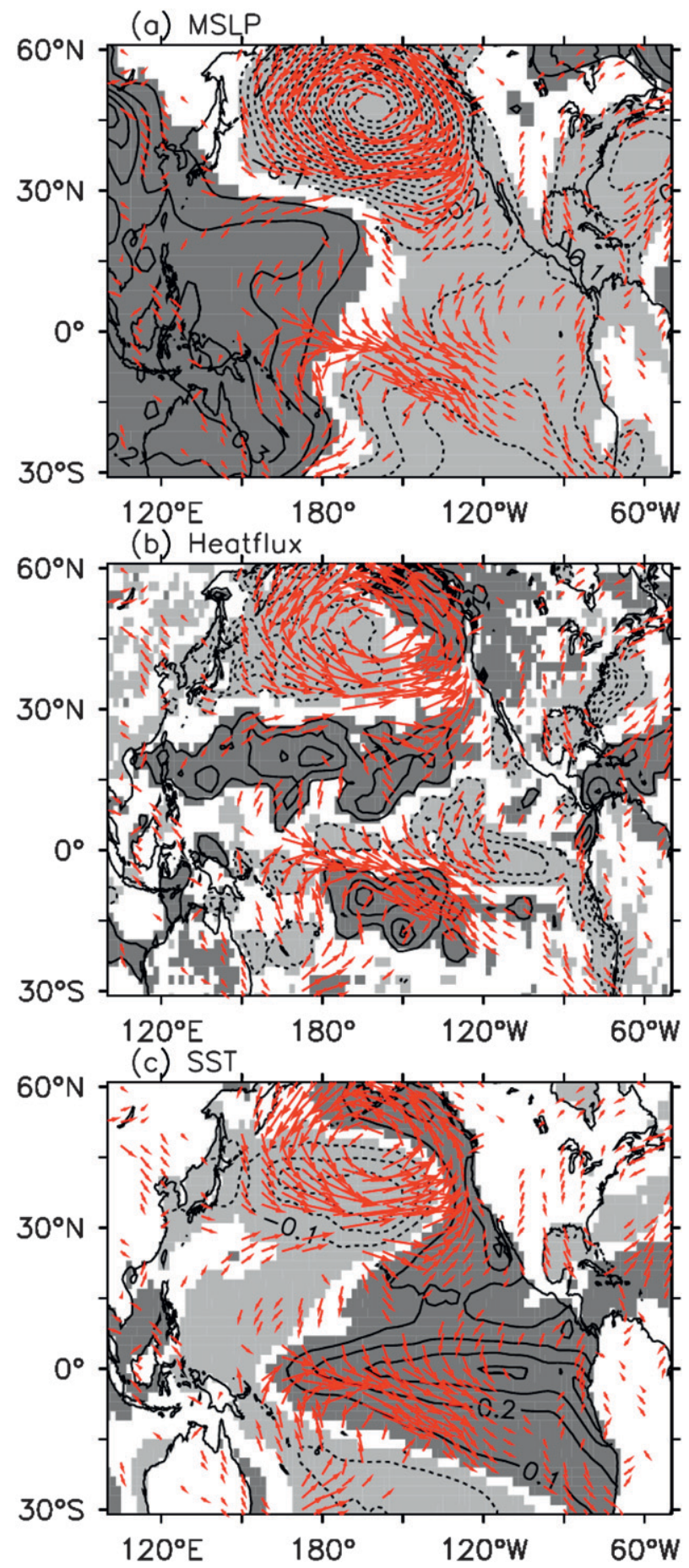

FIG. 5. (a) Pacific SLP, (b) surface heat flux, and (c) SST anomalies regressed with the PC of the first EOF mode (PC1) of extratropical SLP anomalies. Wind vectors at $1000 \mathrm{mb}$ regressed with PC1 are also superimposed. Regression coefficients significant at the $99 \%$ level (Student's $t$ test) are shaded for SLP, surface heat flux, and SST anomalies. Only regressed wind vectors significant at the $99 \%$ level are shown.

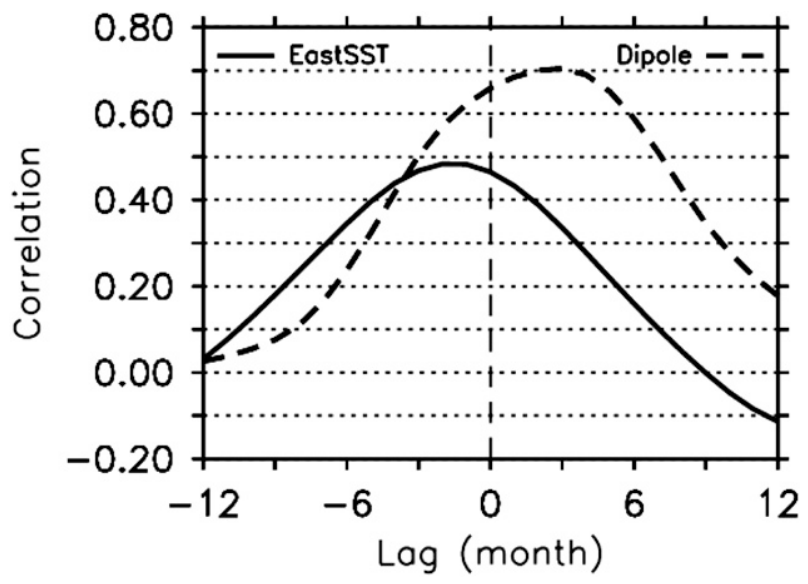

FIG. 6. Lead-lag correlation coefficients between the PC of the first SLP mode and the eastern tropical Pacific SST (solid) and extratropical Pacific SST dipole (dashed) indices. Positive (negative) lags indicate that the PC leads (lags) the SST indices. The eastern Pacific SST index is defined as the SST anomalies averaged in the eastern equatorial Pacific $\left(5^{\circ} \mathrm{S}-5^{\circ} \mathrm{N}, 130^{\circ}-80^{\circ} \mathrm{W}\right)$ and the SST dipole index as the difference between the SST anomalies averaged over the warm $\left(30^{\circ}-45^{\circ} \mathrm{N}, 130^{\circ}-120^{\circ} \mathrm{W}\right)$ and cold $\left(30^{\circ}-45^{\circ} \mathrm{N}, 170^{\circ} \mathrm{E}-\right.$ $\left.150^{\circ} \mathrm{W}\right)$ center regions of the dipole.

The correlations between the two SST indices and PC1 are shown in Fig. 6. The figure indicates that the eastern equatorial Pacific SST index (solid line) leads the Aleutian low variation by one month, which in turn leads the extratropical SST dipole index (dashed line) by three months.

The analyses presented in Figs. 2-6 together suggest that part of the first SLP mode represents an extratropical atmospheric response to tropical SST anomaly forcing (particularly the EP type) and is involved in the atmospheric bridge mechanism that allows the tropical SST anomalies to force the zonal SST anomaly dipole in the North Pacific. These results are consistent with previous studies of ENSO's influences on the Aleutian low and North Pacific Ocean and the atmospheric bridge mechanism (e.g., Horel and Wallace 1981; Pan and Oort 1983; Alexander 1990, 1992a,b; Trenberth and Hurrell 1994; Deser and Blackmon 1995; Lau and Nath 1996; Niebauer 1988; Overland et al. 1999; Alexander et al. 2002; Yeh and Kirtman 2003; DeWeaver and Nigam 2004; Rodionov et al. 2007; and a number of others). But this study emphasizes that the extratropical association is stronger for the EP ENSO and that the bridging mechanism is faster for the EP ENSO than for the CP ENSO.

\section{North Pacific Oscillation and the EP and CP types of ENSO}

We now turn to the relationship between Pacific SST anomalies and the second SLP mode. Figure 7 shows the 


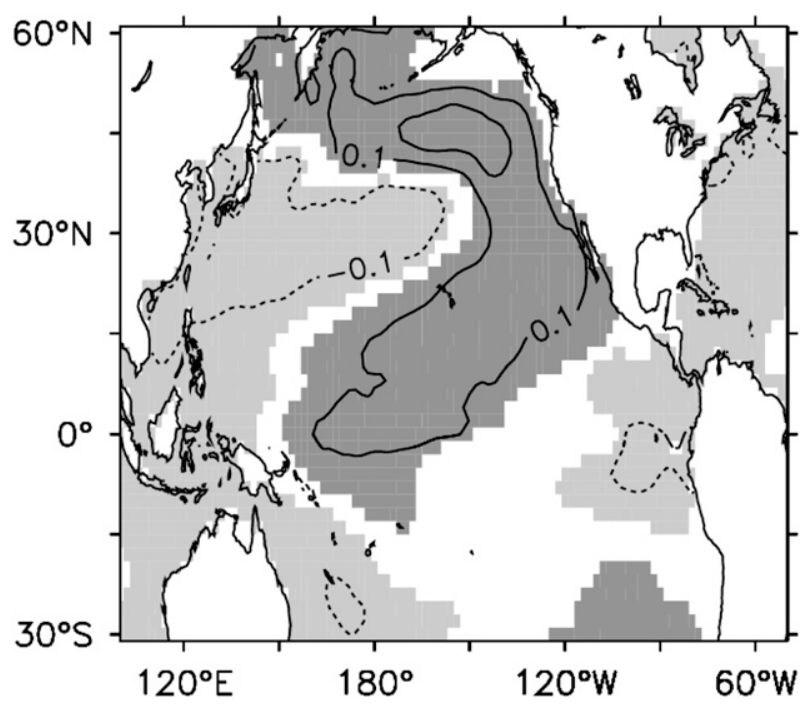

FIG. 7. SST anomalies regressed with the PC of the second EOF mode of extratropical SLP variations. The contour interval is 0.1 and the coefficients that are significant at the $99 \%$ level are shaded.

SST anomalies regressed onto the PC of the second SLP mode. The regression is characterized by a band of positive SST anomalies extending from the northeastern Pacific to the tropical central Pacific, a zonal band of negative SST anomalies along $30^{\circ} \mathrm{N}$, and another band of positive SST anomalies along $50^{\circ} \mathrm{N}$. This meridional SST tripole pattern is different in two major ways from the zonal SST dipole pattern associated with the first SLP mode (see Fig. 2). First, the tripole pattern extends further equatorward than the dipole pattern. While the dipole has most of its SST anomalies located north of $30^{\circ} \mathrm{N}$, the tripole anomalies extend into the tropics. Second, in the tripole pattern large SST anomalies are confined to the eastern part of the Pacific while the dipole pattern has substantial anomalies in the central North Pacific. To explore the linkage between the SST tripole pattern and the second SLP mode further, we show in Fig. 8 the regression of SLP, 1000-mb wind, surface heat flux, and SST anomalies onto the PC of the second SLP mode. The figure shows that in the southeastern quarter of the southern SLP anomaly center, southwesterly anomalies (Fig. 8a) advect warm and moist air into the region to reduce the out-of-the-ocean surface heat flux (i.e., positive heat flux anomalies; Fig. 8b) and consequently produce the positive SST anomaly band that extends toward the central tropical Pacific (Fig. 8c). Conversely, on the western side of the SLP anomaly center, positive zonal wind anomalies strengthen the mean westerlies and enhance the out-of-ocean heat fluxes (i.e., negative surface heat flux anomalies). As a result, a band of negative SST anomalies is produced at around $30^{\circ} \mathrm{N}$. In between this southern SLP anomaly center and the

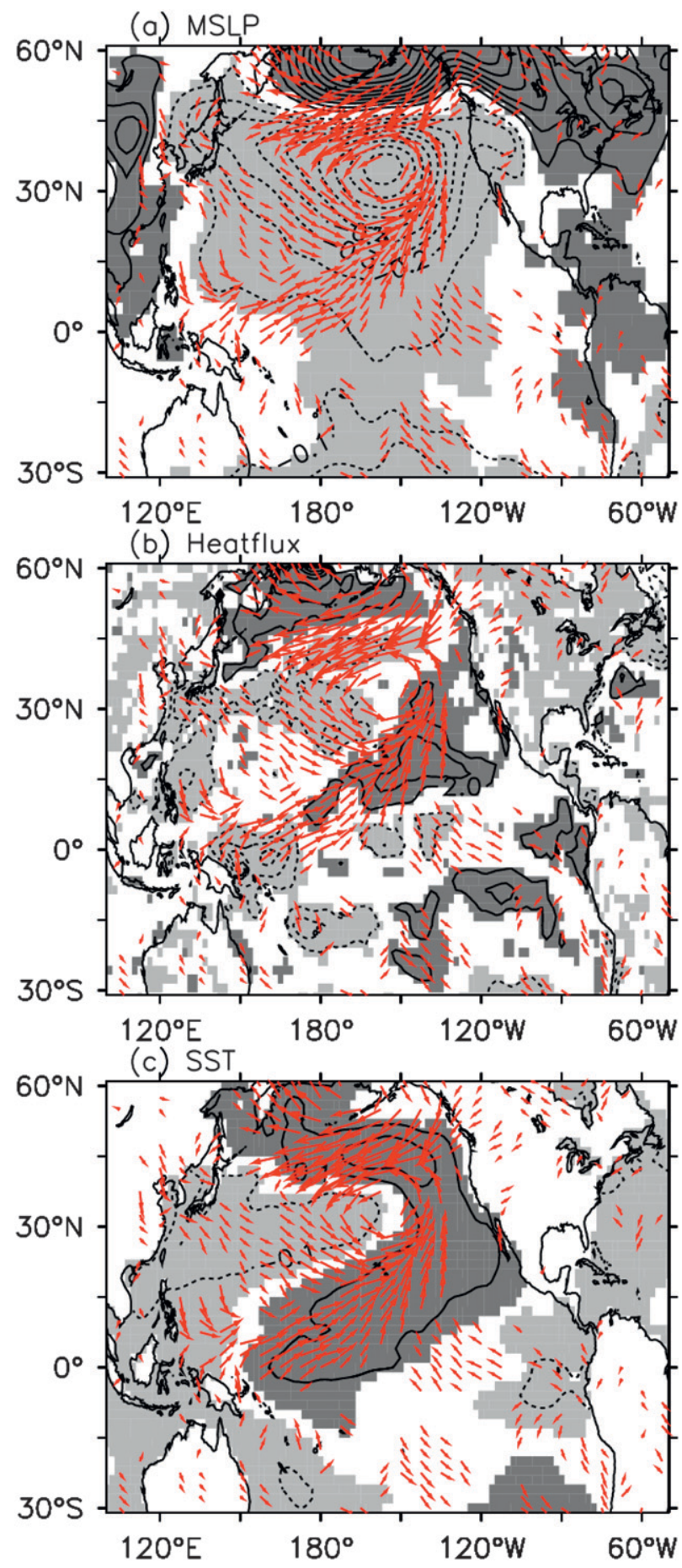

FIG. 8. As in Fig. 5, but for Pacific SLP, surface heat flux, SST, and $1000-\mathrm{mb}$ wind anomalies regressed with the PC of the second EOF mode.

SLP anomaly center to the north, easterly anomalies are generated, which weaken the climatological westerly winds, reduce out-of-ocean surface heat fluxes, and produce a zonal band of positive SST anomalies along $50^{\circ} \mathrm{N}$. 

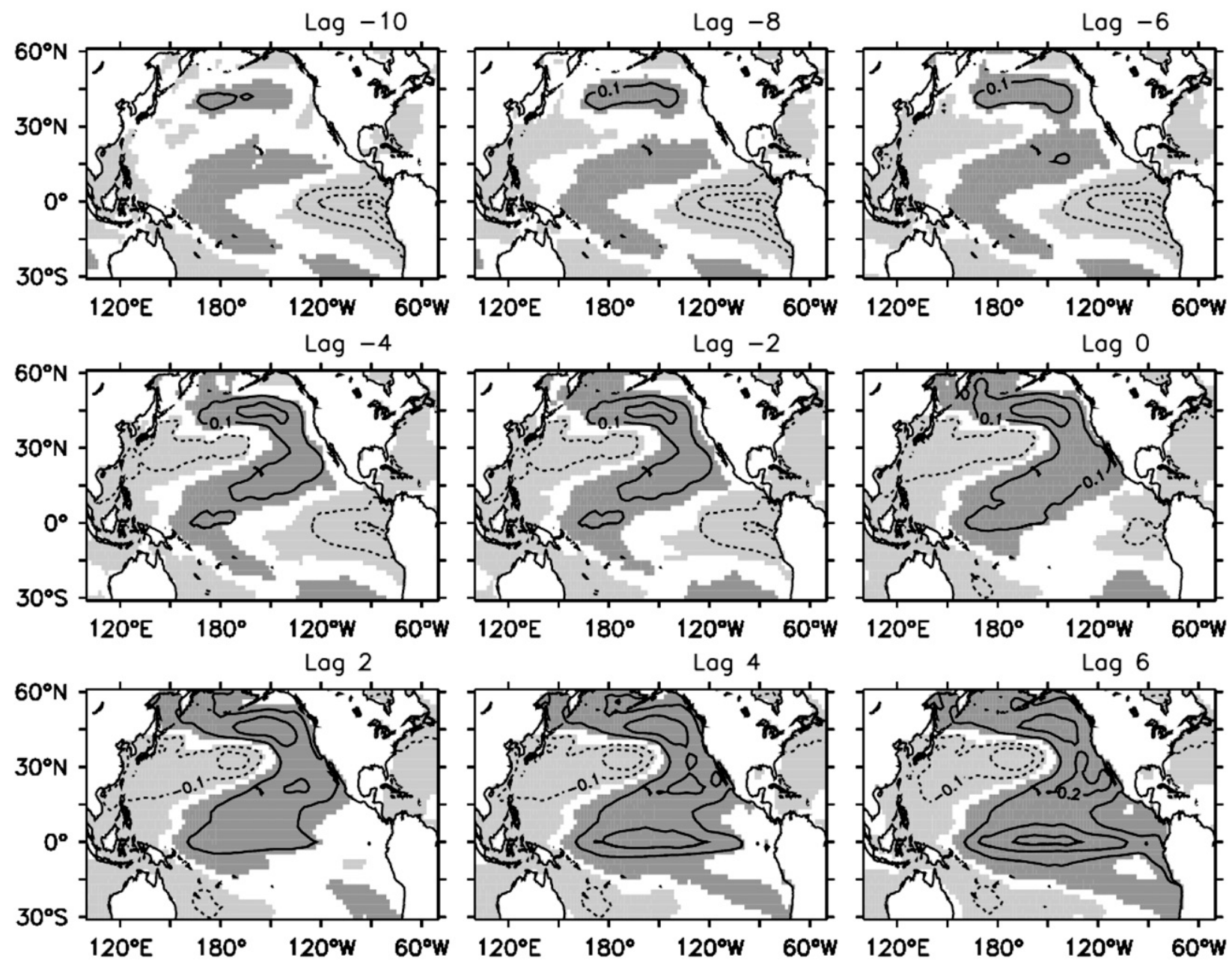

$\operatorname{Lag} 8$
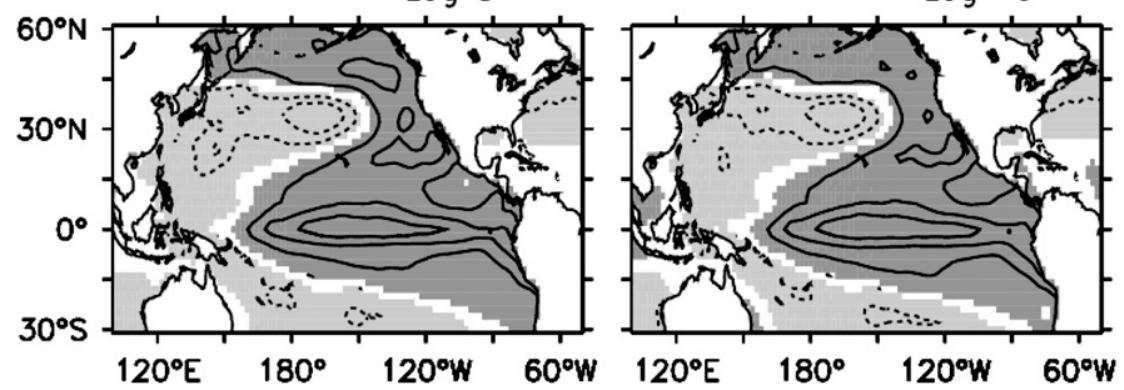

FIG. 9. SST anomalies regressed with the second SLP mode from lag -10 months to lag +10 months. The contour interval is 0.1 and the regression coefficients significant at the 99\% level according to a Student's $t$ test are shaded. Positive lags indicate the PC leads the SST anomalies.

The analysis presented in Fig. 8 indicates that the SST tripole pattern is forced by the surface heat flux anomalies associated with the second SLP mode, particularly its southern anomaly center.

By inspecting the spatial patterns of the regressed lead-lag SST anomalies with the second SLP mode, as shown in Fig. 9, it is noticed that the subtropical SST anomalies induced by the SLP mode can sustain themselves several months after the second SLP mode peaks (i.e., at lag 0 ) and can extend into the central equatorial Pacific. A few months after the peak, positive SST anomalies are established in the central equatorial $\mathrm{Pa}-$ cific (see lags 2-4). These anomalies then intensify rapidly, which is an indication that local air-sea interactions 
have become active in growing the equatorial SST anomalies. About six months after the second SLP mode peaks, a warming pattern is well developed in the central equatorial Pacific. It is also important to point out that this tropical Pacific SST anomaly pattern is similar to the CP type of ENSO described by Kao and Yu (2009) and is different from the EP type associated with the first SLP mode (see Fig. 2). The warming starts from central Pacific rather than the South American coast. Figure 9 indicates that the NPO (i.e., the second SLP mode) serves as an extratropical forcing to the onset of the CP type of ENSO. A possible mechanism for sustaining the subtropical SST anomalies after the NPO peaks is the seasonal footprinting mechanism of Vimont et al. (2001, 2003, 2009). They suggested that the wind-evaporation-SST (WES) feedback mechanism of Xie and Philander (1994) was responsible for sustaining the subtropical SST anomalies for several seasons. These persistent subtropical SST anomalies then force wind anomalies in the central to western equatorial Pacific to initiate tropical SST anomalies. A heat budget analysis of central Pacific SST variability by $\mathrm{Yu}$ et al. (2010) came to a similar conclusion, except that they suggested that ocean advection processes associated with the subtropical surface wind anomalies also contribute to the onset of the equatorial SST anomalies. Their analysis suggested that vertical and meridional ocean advection related to readjustment of the subtropical cell (STC; McCreary and Lu 1994) to the subtropical trade wind changes is important in the onset stage of the central equatorial SST anomalies.

To further examine the relationships between the second SLP mode and the two types of ENSO, lead-lag correlation coefficients between the $\mathrm{PC}$ of the second SLP mode and the CP and EP indices are shown in Fig. 10. For the CP type (Fig. 10b), the largest correlation (0.38, significant at the $99 \%$ level using a Student's $t$ test) occurs when the second SLP mode leads the CP ENSO by eight months, which is consistent with Fig. 9 in that the second SLP mode drives the CP type of SST variations. Figure 10a shows that for the EP ENSO the largest correlation $(-0.47)$ occurs when it leads the SLP mode by six months. This relatively strong correlation indicates that the EP ENSO can force the second SLP mode. To look into this relation further, we show in Fig. 11 the regression of Pacific SLP anomalies onto the EP index at various time lags. During the development and mature phases of the EP ENSO (i.e., from lag -6 to lag 0), the Pacific SLP variations are dominated by negative anomalies around the Aleutian low (i.e., the first SLP mode) and a Southern Oscillation pattern in the tropics. But during the decay phase of the EP ENSO (after lag 0), the positive SLP anomalies in the western Pacific south of the $50^{\circ} \mathrm{N}$ expand toward the central North Pacific. The extratropical SLP
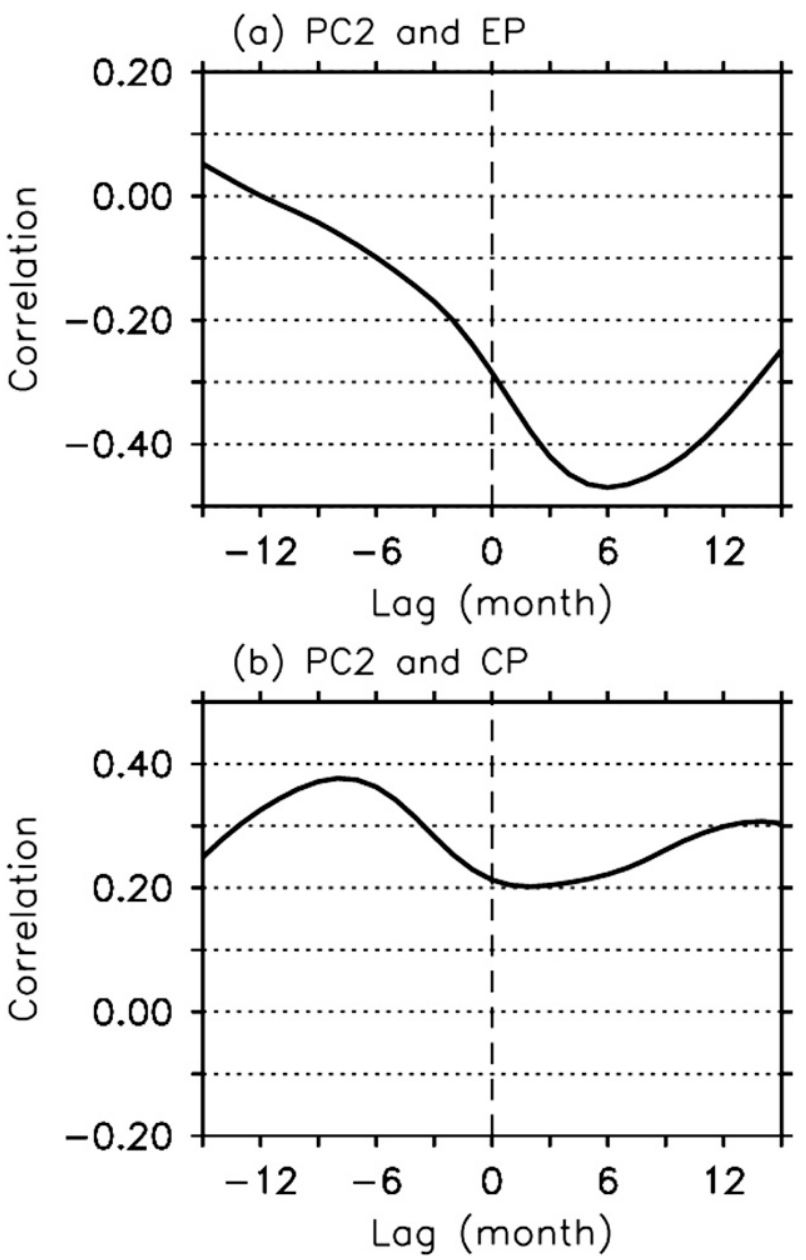

FIG. 10. Lead-lag correlation coefficients between the PC of the second SLP mode and the (a) EP and (b) CP indices. Positive lags indicate the index leads the PC.

anomaly pattern gradually changes to the NPO-like pattern consisting of a seesaw pattern centered at $50^{\circ} \mathrm{N}$. The NPO pattern can be clearly recognized after lag +6 of Fig. 11. We project the regressed SLP patterns of Fig. 11 onto the first and second SLP modes (i.e., Figs. 1a,b) and show the projection coefficients in Fig. 12. This figure shows that the projection coefficient is largest onto the first SLP mode near the mature phase of the EP type and onto the second SLP mode during the decay phase of the EP type.

The cause of the transition of the SLP anomaly patterns requires further study. But it is interesting to find that the EP ENSO can excite the second SLP mode during its decay phase. It implies that the EP ENSO is one of the forcing mechanisms capable of producing the north-south SLP anomaly dipole in the extratropical atmosphere (i.e., the NPO). Since the largest correlation between the second SLP mode and the EP ENSO is - 0.47 (from Fig. 10), 

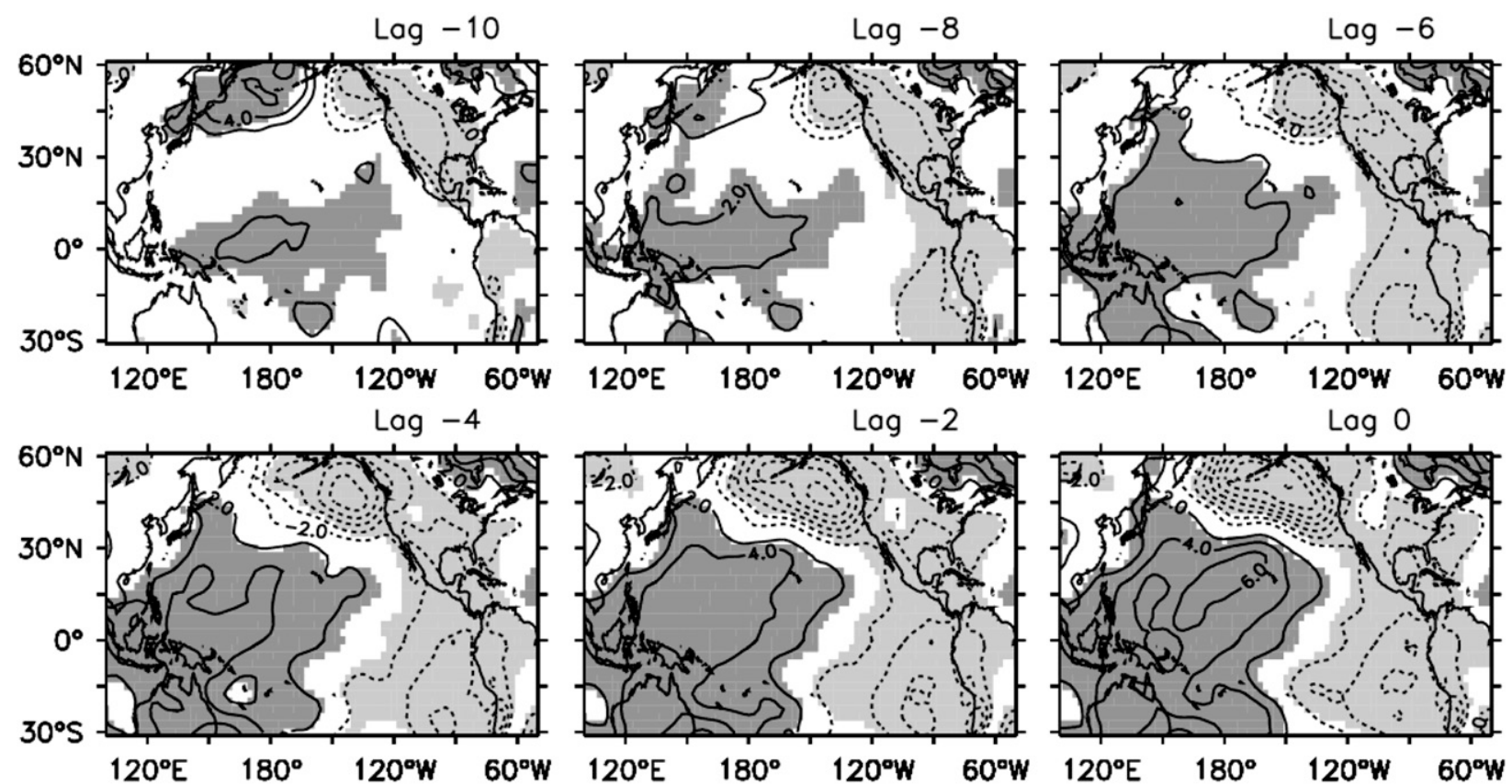

Lag 2
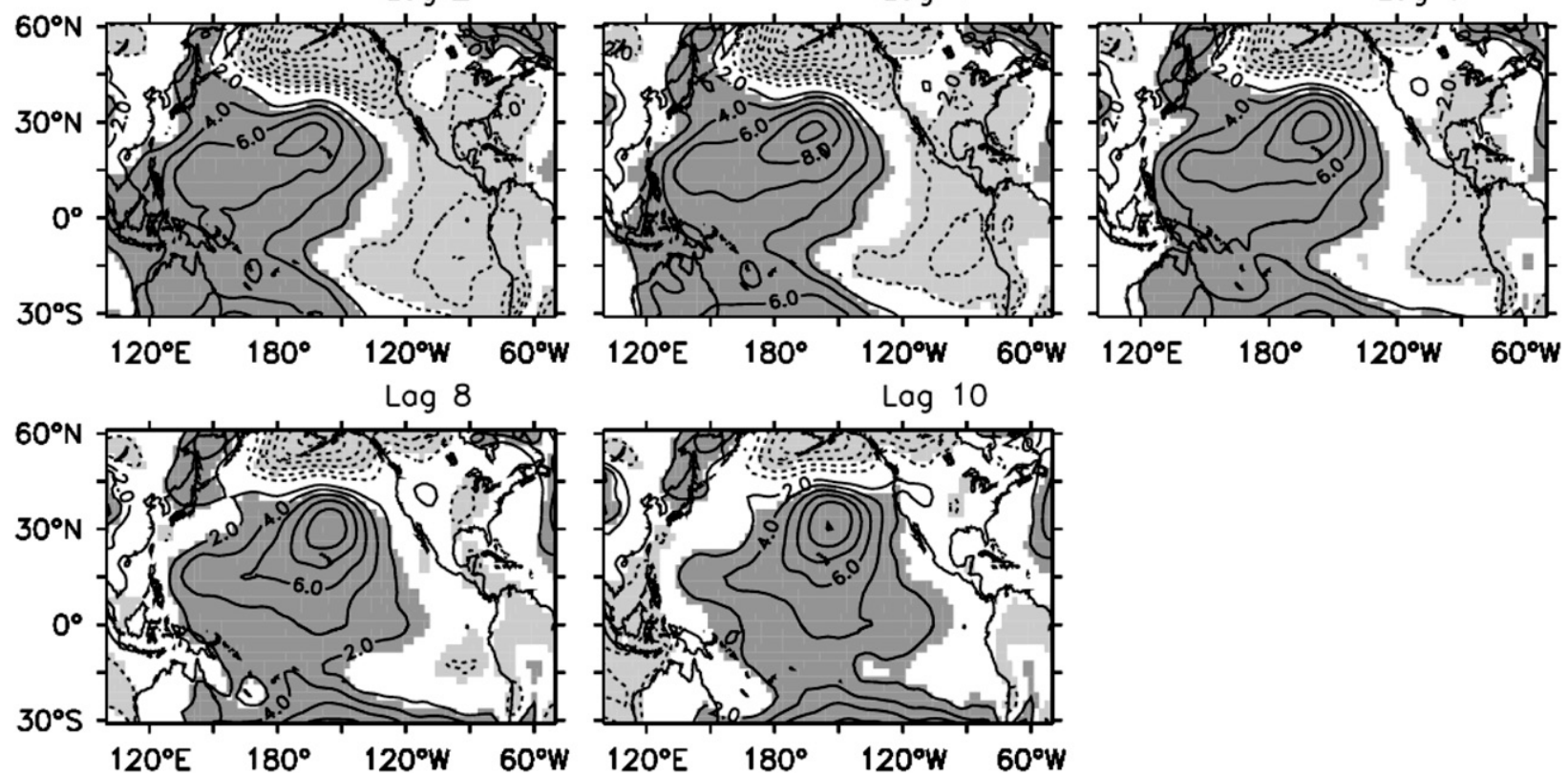

FIG. 11. SLP anomalies regressed with the EP index from lag -10 months to lag +10 months. The contour interval is 4.0 , and values significant at the $99 \%$ level are shaded. Positive lags indicated that the EP index leads the SLP anomalies.

about $22 \%$ of the NPO can be attributed to the EP type of tropical Pacific warming and cooling events. As we have already pointed out, the second SLP mode can lead to the CP ENSO; it is therefore possible that some of the CP events are excited after by the demise of EP events through the second EOF mode of extratropical SLP variations. Armed with this speculation, we go back to Fig. 9 to inspect the SST anomalies regressed with the second SLP mode. We notice that before the second SLP mode peaks at lag 0 , a La Niña event is decaying in the eastern Pacific (i.e., from lag -10 to lag 0). Consistent with the negative correlation between the second SLP mode and the EP index, Fig. 9 indicates that as a cold (warm) phase of the EP ENSO decays, a positive (negative) phase of the second SLP mode develops in the extratropical Pacific, which can then drive a warm (cold) 

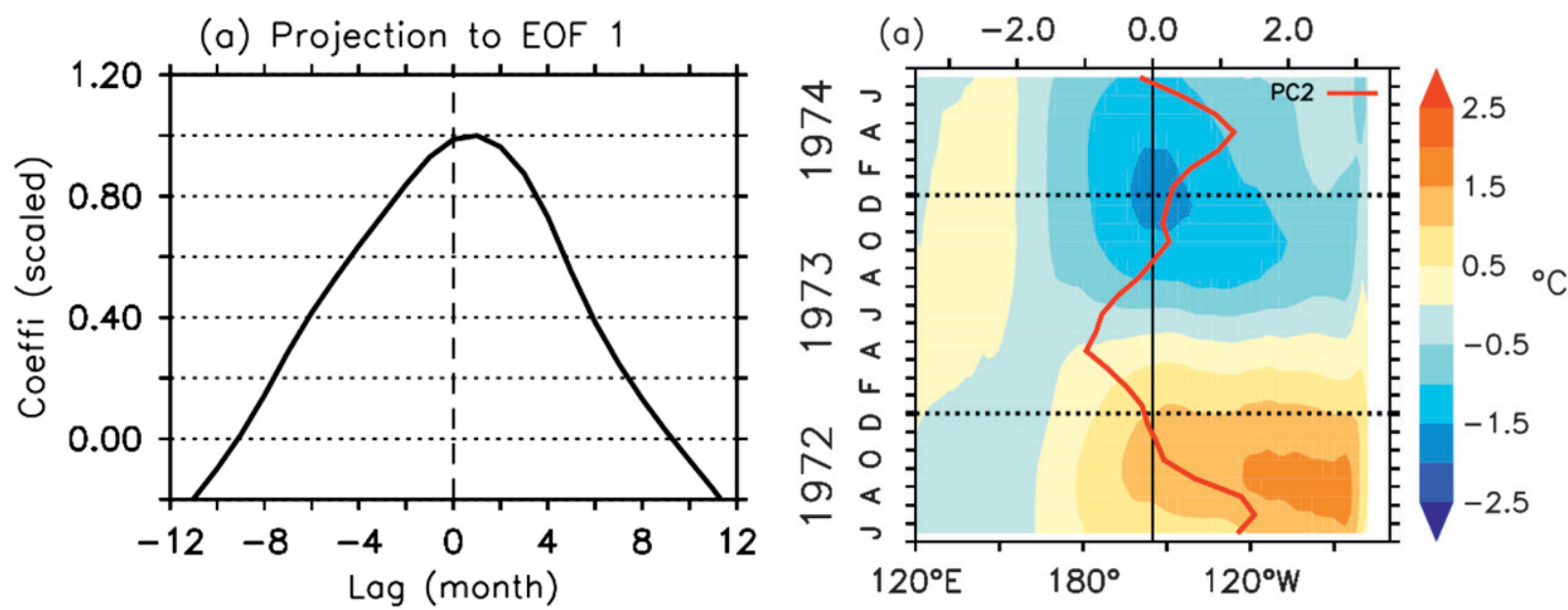

(b) Projection to EOF 2
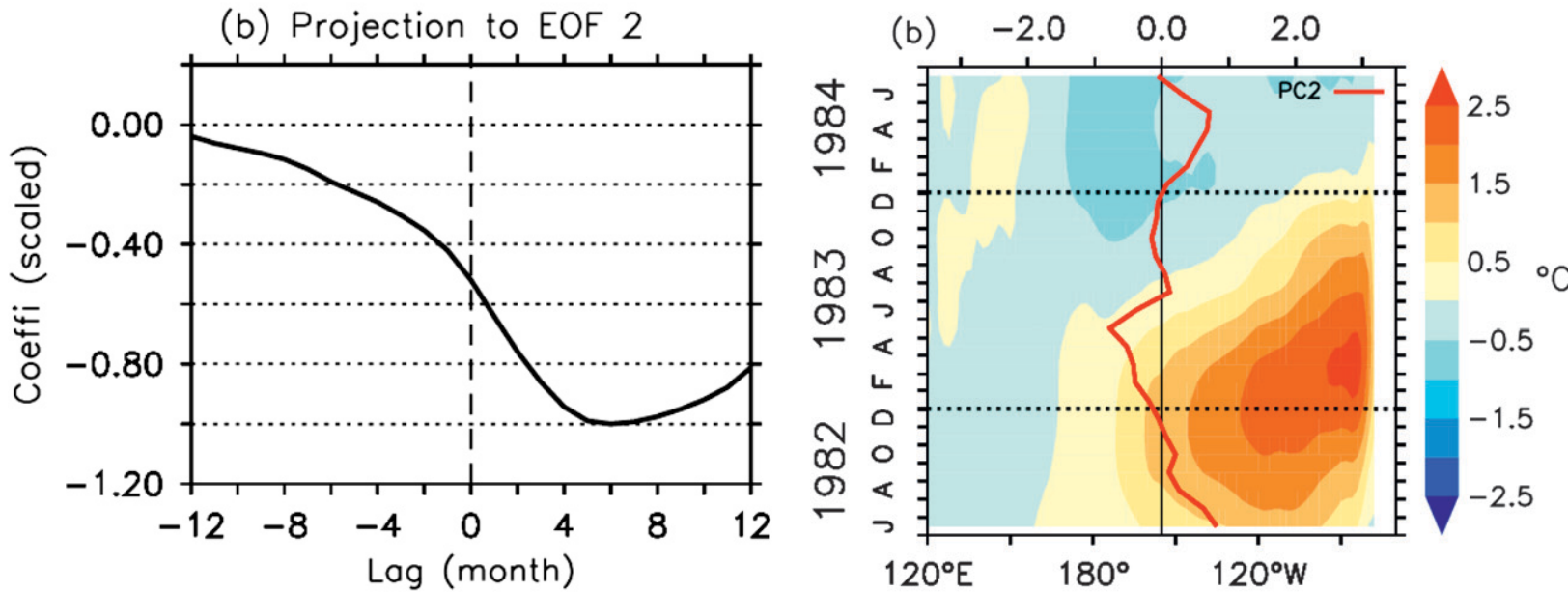

FIG. 12. Projection coefficients of the regressed SLP anomalies of Fig. 11 onto the (a) first and (b) second EOF modes of the extratropical SLP variations. The coefficients are scaled by their maximum absolute values.

phase of CP ENSO a few months later. The occurrences of CP and EP types of ENSO can, therefore, be linked in sequence by the second mode of extratropical SLP variations. This is another kind of atmospheric bridge mechanism, but this bridge links the two different types of tropical Pacific SST variability.

This "extratropical linking mechanism" may be a reason why strong CP-type La Niña events tend to occur after strong EP-type El Niño events, as noted in Yu et al. (2011). For instance, the strong CP La Niña events of 1973/74, 1983/84, and 1998/99 came after the strong EP El Niño events of 1972/73, 1982/83, and 1997/98, respectively. To further verify this linking mechanism, we display in Fig. 13 the evolution of equatorial $\left(5^{\circ} \mathrm{S}-5^{\circ} \mathrm{N}\right)$ SST anomalies (contours) from these three sets of events and the corresponding principal component values (red line) of the second SLP mode. The figure shows that all three CP La Niña events $(1973,1983$, and 1998) were

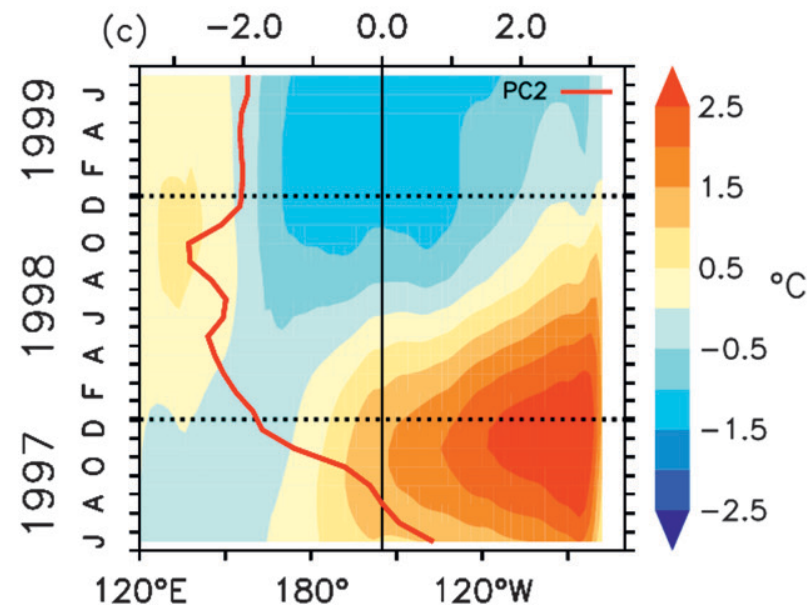

FIG. 13. Evolution of equatorial $\left(5^{\circ} \mathrm{S}-5^{\circ} \mathrm{N}\right)$ SST anomalies (contours) for three EP El Niños followed by CP-type La Niñas: (a) 1972/73 El Niño and 1973/74 La Niña, (b) 1982/83 El Niño and 1983/84 La Niña, and (c) 1997/98 El Niño and 1998/99 La Niña. Superimposed is the PC (red line) of the second SLP mode during the evolution of the events. 
preceded by a negative $\mathrm{PC}$ value in the previous spring, and all these negative $\mathrm{PC}$ values began to increase after the EP El Niño events began to decay. All three of these events show a sequence of EP El Niño, second SLP mode, and CP La Niña, consistent with the extratropical linking mechanism suggested by this study. It should be noted that while our results suggest that some $\mathrm{CP}$ events may be induced by EP events via the second SLP mode, we do not exclude other possible generation mechanisms for the CP ENSO. Also, given the limited number of available cases in observations, further studies (e.g., using state-ofthe art coupled models) are needed to further confirm this observed EP-to-CP transition.

\section{Conclusions and discussion}

In this study, we linked the two leading EOF modes of extratropical SLP variations to the EP and CP types of ENSO. The first SLP mode is associated with interannual variability of the Aleutian low and can be excited as an extratropical response to the both types of ENSO. The warm phase (El Niño) of ENSO enhances the strength of the Aleutian low (i.e., negative SLP anomalies), and the cold phase (La Niña) weakens it (i.e., positive SLP anomalies). This study finds that the Aleutian low has a stronger and more immediate response to the EP type of ENSO than to the CP type. The tropicalextratropical teleconnection appears to act more slowly for the CP ENSO. The second SLP mode is characterized by a meridional seesaw pattern in the central Pacific with a nodal point near $50^{\circ} \mathrm{N}$. This SLP anomaly pattern resembles the NPO. It is found that this SLP mode can force the onset of the CP type of ENSO.

Our results are consistent with many previous studies that have suggested that tropical SST variations can force extratropical SLP variability and that extratropical SLP variations are precursors to tropical SST variability. However, this study is able to link these two different tropical-extratropical relationships separately to the EP and CP types of ENSO: 1) the EP type is more important than the CP type in forcing the extratropical SLP variability (which projects to both the Aleutian low variation and the NPO), 2) the second EOF mode of the extratropical SLP variability is crucial to the generation of the CP type of ENSO, and 3) the NPO offers an extratropical linking mechanism connecting the occurrence sequence of the EP and CP types of ENSO. This linking mechanism may play some role in determining the SST propagation direction of ENSO events. The second linkage substantiates the suggestion of Yu et al. (2010) that a significant part of the SST variability in the central equatorial Pacific is excited by extratropical atmospheric forcing. It should be noted that the zonal advection of mean SST by anomalous zonal currents plays a key role in developing the CP El Niño, as suggested by Kug et al. (2009) and Yu et al. (2010). However, as Yu et al. (2010) pointed out, the zonal advection process is important only after SST anomalies become established in the central equatorial Pacific. The initial establishment of the equatorial SST anomalies is related to the extratropical forcing. Our results do not exclude the suggestion by Yu et al. (2009) that the CP ENSO can also be excited by Asian and Australian monsoon forcing, since it is known that monsoon heating has an important influence on subtropical and extratropical sea level pressure variations (e.g., Chen et al. 2001).

Acknowledgments. We thank two anonymous reviewers for the helpful comments. This research was supported by NSF (ATM-0925396).

\section{REFERENCES}

Alexander, M. A., 1990: Simulation of the response of the North Pacific Ocean to the anomalous atmospheric circulation associated with El Niño. Climate Dyn., 5, 53-65.

, 1992a: Midlatitude atmosphere-ocean interaction during El Niño. Part I: The North Pacific Ocean. J. Climate, 5, 944-958. , 1992b: Midlatitude atmosphere-ocean interaction during El Niño. Part II: The Northern Hemisphere atmosphere. J. Climate, 5, 959-972.

—, I. Bladé, M. Newman, J. R. Lanzante, N.-C. Lau, and J. D. Scott, 2002: The atmospheric bridge: The influence of ENSO teleconnections on air-sea interaction over the global oceans. J. Climate, 15, 2205-2231.

An, S.-I., 2003: Conditional maximum covariance analysis and its application to the tropical Indian Ocean SST and surface wind stress anomalies. J. Climate, 16, 2932-2938.

Anderson, B. T., 2003: Tropical Pacific sea-surface temperatures and preceding sea level pressure anomalies in the subtropical North Pacific. J. Geophys. Res., 108, 4732, doi:10.1029/ 2003JD003805.

_ 2004: Investigation of a large-scale mode of ocean-atmosphere variability and its relation to tropical Pacific sea surface temperature anomalies. J. Climate, 17, 4089-4098.

Ashok, K., S. Behera, A. S. Rao, H. Weng, and T. Yamagata, 2007: El Niño Modoki and its teleconnection. J. Geophys. Res., 112, C11007, doi:10.1029/2006JC003798.

Chang, P., L. Zhang, R. Saravanan, D. J. Vimont, J. C. H. Chiang, L. Ji, H. Seidel, and M. K. Tippett, 2007: Pacific meridional mode and El Niño-Southern Oscillation. Geophys. Res. Lett., 34, L16608, doi:10.1029/2007GL030302.

Chen, P., M. P. Hoerling, and R. M. Dole, 2001: The origin of the subtropical anticyclones. J. Atmos. Sci., 58, 1827-1835.

Deser, C., and M. L. Blackmon, 1995: On the relationship between tropical and North Pacific sea surface temperature variations. J. Climate, 8, 1677-1680.

DeWeaver, E., and S. Nigam, 2004: On the forcing of ENSO teleconnections by anomalous heating and cooling. J. Climate, 17, 3225-3235.

Horel, J. D., and J. M. Wallace, 1981: Planetary-scale atmospheric phenomena associated with the Southern Oscillation. Mon. Wea. Rev., 109, 813-829. 
Kao, H.-Y., and J.-Y. Yu, 2009: Contrasting eastern-Pacific and central-Pacific types of El Niño. J. Climate, 22, 615-632.

Kidson, J. W., 1975: Eigenvector analysis of monthly mean surface data. Mon. Wea. Rev., 103, 177-186.

Kim, H.-M., P. J. Webster, and J. A. Curry, 2009: Impact of shifting patterns of Pacific Ocean warming events on North Atlantic tropical cyclones. Science, 325, 77-80.

Kistler, R., and Coauthors, 2001: The NCEP-NCAR 50-Year Reanalysis: Monthly means CD-ROM and documentation. Bull. Amer. Meteor. Soc., 82, 247-268.

Kug, J.-S., F.-F. Jin, and S.-I. An, 2009: Two types of El Niño events: Cold tongue El Niño and warm pool El Niño. J. Climate, 22, 1499-1515.

Kutzbach, J. E., 1970: Large-scale features of monthly mean Northern Hemisphere anomaly maps of sea-level pressure. Mon. Wea. Rev., 98, 708-716.

Larkin, N. K., and D. E. Harrison, 2005: On the definition of El Niño and associated seasonal average U.S. weather anomalies. Geophys. Res. Lett., 32, L13705, doi:10.1029/2005GL022738.

Lau, N.-C., and M. J. Nath, 1996: The role of the "atmospheric bridge" in linking tropical Pacific ENSO events to extratropical SST anomalies. J. Climate, 9, 2036-2057.

McCreary, J. P., and P. Lu, 1994: On the interaction between the subtropical and equatorial ocean circulation: The subtropical cell. J. Phys. Oceanogr., 24, 466-497.

Mo, K. C., and R. W. Higgins, 1998: Tropical convection and precipitation regimes in the western United States. J. Climate, 11, 2404-2423.

Niebauer, H. J., 1988: Effects of El Niño-Southern Oscillation and North Pacific weather patterns on interannual variability in the subarctic Bering Sea. J. Geophys. Res., 93, 5051-5068.

Overland, J. E., J. M. Adams, and N. A. Bond, 1999: Decadal variability in the Aleutian low and its relation to high-latitude circulation. J. Climate, 12, 1542-1548.

Pan, H. Y., and A. H. Oort, 1983: Global climate variations connected with sea surface temperature anomalies in the equatorial Pacific Ocean for the 1958-1973 period. Mon. Wea. Rev., 111, 1244-1258.

Rodionov, S., N. Bond, and J. Overland, 2007: The Aleutian low, storm tracks, and winter climate variability in the Bering Sea. Deep-Sea Res., 54, 2560-2577.

Rogers, J. C., 1981: The North Pacific Oscillation. J. Climatol., 1, $39-57$.

Smith, T. M., and R. W. Reynolds, 2003: Extended reconstruction of global sea surface temperatures based on COADS data (1854-1997). J. Climate, 16, 1495-1510.
Trenberth, K. E., and J. W. Hurrell, 1994: Decadal atmosphericocean variations in the Pacific. Climate Dyn., 9, 303-319.

Vimont, D. J., D. S. Battisti, and A. C. Hirst, 2001: Footprinting: A seasonal connection between the tropics and mid-latitudes. Geophys. Res. Lett., 28, 3923-3926.

_ J. M. Wallace, and D. S. Battisti, 2003: The seasonal footprinting mechanism in the Pacific: Implications for ENSO. J. Climate, 16, 2668-2675.

—, M. Alexander, and A. Fontaine, 2009: Midlatitude excitation of tropical variability in the Pacific: The role of thermodynamic coupling and seasonality. J. Climate, 22, 518-534.

Walker, G. T., and E. W. Bliss, 1932: World weather V. Mem. Roy. Meteor. Soc., 4, 53-84.

Wallace, J. M., and D. S. Gutzler, 1981: Teleconnections in the geopotential height field during the Northern Hemisphere winter. Mon. Wea. Rev., 109, 784-812.

Weng, H., S. K. Behera, and T. Yamagata, 2009: Anomalous winter climate conditions in the Pacific Rim during recent El Niño Modoki and El Niño events. Climate Dyn., 32, 663-674.

Xie, S.-P., and S. G. H. Philander, 1994: A coupled ocean-atmosphere model of relevance to the ITCZ in the eastern Pacific. Tellus, 46A, 340-350.

Yeh, S.-W., and B. P. Kirtman, 2003: On the relationship between the interannual and decadal SST variability in the North Pacific and tropical Pacific Ocean. J. Geophys. Res., 108, 4344, doi:10.1029/2002JD002817

—, J.-S. Kug, B. Dewitte, M.-H. Kwon, B. P. Kirtman, and F.-F. Jin, 2009: El Niño in a changing climate. Nature, 461, 511-514.

Yu, J.-Y., and H.-Y. Kao, 2007: Decadal changes of ENSO persistence barrier in SST and ocean heat content indices: 1958-2001. J. Geophys. Res., 112, D13106, doi:10.1029/ 2006JD007654.

_ W. T. Liu, and C. R. Mechoso, 2001: The SST anomaly dipole in the northern subtropical Pacific and its relationship with ENSO. Geophys. Res. Lett., 27, 1931-1934.

- F. Sun, and H.-Y. Kao, 2009: Contributions of Indian Ocean and monsoon biases to the excessive biennial ENSO in CCSM3 J. Climate, 22, 1850-1858.

_, H.-Y. Kao, and T. Lee, 2010: Subtropics-related interannual sea surface temperature variability in the central equatorial Pacific. J. Climate, 23, 2869-2884.

, and S. T. Kim, 2011: Subsurface ocean temperature indices for central-Pacific and eastern-Pacific types of El Niño and La Niña events. Theor. Appl. Climatol., in press, doi:10.1007/s00704-010-0307-6. 